\title{
The challenges and experiences of stroke
their spouses in Blantyre, Malawi
Reuben Kalavina ${ }^{1}$ Enock Chisati ${ }^{2}$, Nondwe Mlenzana ${ }^{1}$, Margaret Wazakili ${ }^{2}$
}

\author{
1.University of the Western Cape \\ 2. University of Malawi College of Medicine
}

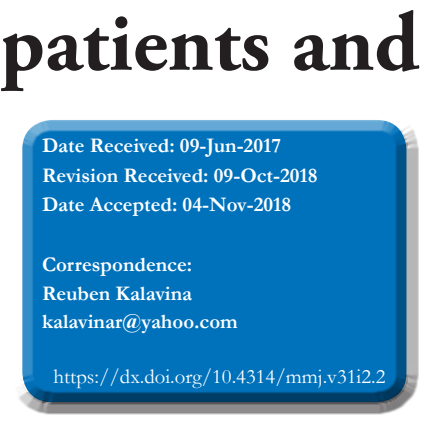

\begin{abstract}
Stroke is the second major cause of death and disability worldwide. Most stroke survivors experience various challenges due to physical and mental impairments which increase the burden on spouses during care. The broad aim of this study was to explore the challenges and experiences of stroke patients and their spouses during and after rehabilitation at the Rehabilitation Centre in Blantyre, Malawi. Methods

This was a qualitative exploratory study design. We conveniently selected 18 participants. Half of the population comprised patients and the other half spouses. Data were collected through in-depth interviews and focus group discussions and were analysed using thematic content analysis.

Results

Stroke patients were found to be challenged by lack of mobility and failure to perform basic functional activities such as walking and feeding using the affected hand, which resulted in sudden dependence on the spouse for basic self-care and daily activities. In consequence, spouses were burdened by care-giving responsibilities while, on the other hand, most participants had limited access to rehabilitation and health services at the grassroots level. Moreover, congestion and lack of privacy were shown to exist at the Kachere Rehabilitation Centre due to inadequate space.

Conclusion

This study has managed to show some of the problems that stroke patients and spouses experience during and after rehabilitation. There is a need for early and adequate intervention to address functional limitations and facilitate return to work. Spouses should be made to understand the condition of their partner and educated regarding possible implications of the same. In addition, social and psychological support should form an inseparable part of the therapy. Stroke support groups and association could be considered as a way of enhancing social support and awareness.
\end{abstract}

\section{Introduction}

An estimated 16 million people are affected by disability due to stroke while six million deaths are recorded annually worldwide $^{1}$. Stroke is the second major cause of death and disability worldwide ${ }^{1}$. Although the incidence of stroke has declined considerably in high income countries including the United Kingdom, it remains a burden facing developing countries especially sub-Saharan countries in terms of disability and mortality ${ }^{2}$. Literature shows that many hospital admissions and deaths are reported in Africa every year due to stroke ${ }^{3,4}$. In Africa, limited healthcare services and personal preferences for traditional remedies have resulted in the under-reporting of stroke-related illnesses ${ }^{5,6}$. However the sub-Saharan Africa is still known for its high burden of disease despite having the lowest density of healthcare providers and institutions ${ }^{7}$. Globally, $60 \%$ of stroke patients acquire permanent disabilities and experience limitations in terms of mobility, vision, voice, speech, swallowing and sexual function ${ }^{8}$. Impairments caused by stroke in patients may cause loss of independence in self-care activities and mobility, which increases responsibility and burden on the spouse, family and community ${ }^{9}$.In addition, financial challenges in some cases also arise as a result of reduced income caused by failure of the stroke survivor to return to their previous occupation due to limitations in terms of activity and participation. Moreover, stroke patients are sidelined and usually face social stigma in different environmental setting $\mathrm{s}^{10,11}$. Spousal care-giving is a physically and emotionally demanding responsibility which reduces quality of life $\mathrm{e}^{3,9,12,13}$. Spouses are expected to transfer their partners several times a day and this highly strenuous activity causes fatigue, sleep disturbance, weight loss and indigestion which together increase the risk of mortality ${ }^{9,13,14}$. Lack of interaction and witnessing the suffering of a loved one may cause emotional and psychological trauma ${ }^{15}$. The underlying challenges have neither been described nor documented in Blantyre, Malawi. It is unlikely that the challenges are the same as those experienced in high income or neighbouring countries because in contrast with most developed and neighbouring countries which have well developed rehabilitation services, Malawi is a low income country with underdeveloped health facilities including only one medical rehabilitation centre in Blantyre city while no rehabilitation services are available in district hospitals ${ }^{7,16-19}$. Therefore, the focus of this study was to explore the challenges and experiences of stroke patients and their spouses in Blantyre, Malawi.

\section{Methodology}

\section{Design}

A qualitative, exploratory design was utilised to investigate the challenges and experiences of stroke patients and spouses in Blantyre, Malawi. An exploratory design is usually conducted to make preliminary investigations into relatively unknown areas of research so as to gain insight into a situation, phenomenon, community or person ${ }^{20}$. 


\section{Setting}

The study took place at the Kachere Rehabilitation Centre in Blantyre and surrounding communities. This is the only adult medical rehabilitation centre in Malawi. It has a 40-bed capacity, 30 of which are non-fee-paying and 10 make up the private wing. This centre offers physiotherapy, occupational therapy, basic speech therapy and nursing services to patients that are admitted from all over the country through an organised referral system. The centre offers free services to all inpatients in the non-fee-paying ward but outpatients and patients in the private wing do pay. The centre is run by a non-governmental organisation but receives funding from Ministry of Health and donations from other institutions and well-wishers. Most of the patients admitted at the centre have neurological disorders such as spinal cord injuries, head injuries, peripheral neuropathies and stroke.

\section{Sampling}

The population of the study consisted of couples one of whom one had suffered a stroke. These participants were purposively selected. In purposive sampling, participants are selected based on their knowledge of the phenomenon under study $^{20} .18$ participants (nine dyads of patients with stroke and spouses) were purposively selected from a population of 183 stroke patients who were admitted to the centre between January, 2011 and March, 2013, and 183 care-giving spouses. The selection criteria were based on marriage (only married couples who were living together at the time the stroke occurred were recruited), stage of illness (only sub-acute and chronic stages were enrolled, acute cases were excluded because the centre only receives patients in sub-acute or chronic stages after the acute phase is already spent in a hospital), setting (enrolled both rural and urban dwellers), social economic status (both paying and non-paying), and severity of disability due to stroke (inpatient and outpatients; usually outpatients had mild disability). Data were collected until saturation in this case two couples were added to attain saturation.

\section{Data collection methods}

Semi-structured in-depth interviews and focus group discussions were utilised to collect data. Semi-structured indepth interviews are effective when exploring and identifying human experiences ${ }^{21}$. Focus group discussions were used to methodologically triangulate and enrich the data. Powell \& Single observed that an effective use of the two methods produced rich and dependable data in qualitative research. In this study, all the participants were interviewed separately at their homes or at the Rehabilitation Centre for an average of 30 to 45 minutes $^{22}$. The principle researcher was allocated one of the outpatient rooms which he used to conduct in-depth interviews. Patients who were admitted at the centre during the study and spouses who were taking care of the patients were interviewed in this particular room. However, spouses who were not present at the centre and those who were already discharged at the time of the study were followed and interviewed at their respective homes. The researchers interviewed every participant separately. The principle researcher conducted all the interviews himself and except only one which was conducted in English, all the others were conducted in the vernacular language (Chichewa). All interviews were recorded using a voice recorder while notes were taken by hand and observations were made to gestures and body movements. Participants at the centre were accessed through the admission register while those discharged were accessed through their contact details as found in the discharge register. In addition, focus group discussions were conducted. A focus group discussion is usually composed of one or two researchers and an interactive group of six to 12 participants that are assembled by the researcher to discuss and comment from personal experience on the topic which is the subject of research ${ }^{21,22}$. Focus group discussions are effective in helping the researchers learn about a wide range of perspectives and social norms of the community or subgroup ${ }^{20,21}$. Two focus group discussions were conducted in this study; one involving patients and the other involving spouses. The former was attended by five patients and the latter by four spouses. However, all the participants had already participated in in-depth interviews before participating in the focus group discussions. Both focus group discussions were conducted in Chichewa at the centre's boardroom and each took an average of one and half hours. The principle researcher explained to the participants the objective of the research. The participants were given information sheets and signed consent forms before participating in the study. Data were collected until saturation was reached. Data collection period was March and May, 2013.

\section{Data analysis}

Data were analysed manually by the principle researcher using thematic content analysis. This is a systematic process of analysing and extracting meaning from data by assigning codes, themes or patterns ${ }^{23,24}$. The interviews were transcribed verbatim by a private professional transcriber based at the University of Malawi, College of Medicine. Backward translation was utilised to translate the transcripts from Chichewa to English and back to English by two experts in languages based at University of Malawi, Chancellor College in Zomba before analysis. The analytic process began with repetitive reading of transcripts and verifying the accuracy of transcripts by listening to the recordings. Then, words carrying similar meaning or concepts were highlighted with similar colours and were condensed to units of general meaning irrespective of whether they answered the research question or not. The units of general meaning which answered the research question were re-named units of relevant meaning. The researcher then determined which units of relevant meaning naturally clustered together. The clusters of meaning were further condensed to form determining themes. Using this process, the researcher arrived at codes, categories and themes.

\section{Trustworthiness}

Trustworthiness is one of the ways of ensuring rigor without sacrificing the relevance of the research ${ }^{25,26}$. In this study, trustworthiness was achieved through member checking as data were taken back to the participants for verification. This process allows participants to review findings from the data analysis in order to conform to the challenge of accuracy of work and this process is central to qualitative research ${ }^{13,18,27}$. In addition, triangulation of data collection methods and a clear description of the research methods were used to achieve trustworthiness. In this case, the researchers presented the process of obtaining the finding in a way that is explicit and repeatable through tracking of the research design ${ }^{13,18,27}$. Trustworthiness was also achieved through audit trail, that is, the principle researcher allowed peer researchers, student advisors and colleagues in the field to examine the findings at different stages of data analysis and interpretation ${ }^{13,18,27}$. 
Furthermore, the researchers utilised peer debriefing to achieve trustworthiness. This was achieved through dialogue and consultations of colleagues and experts who had experience with the topic and methodology used, which approach was used to minimise the effects of bias ${ }^{13,18,27}$.

\section{Ethical considerations}

Ethical approval was obtained from the Research Grants and Study Leave Committee of the University of the Western Cape (reference number 13/2/29) and from the College of Medicine Research Ethics Committee, University of Malawi (reference number P. 03/13/1369). Further approval was obtained from the General Manager of Malawi Against Physical Disabilities, and informed consent was obtained from the participants. All measures were taken to protect the rights and feelings of participants, and all participants remained anonymous by use of numbers and alphabetical letters instead of names. Furthermore, all participants were assured about confidentiality and the right to withdraw from the study without any consequences. However, there was low attendance during focus group discussion owing to problems with transportation because a good number of the participants were residing outside Blantyre and a good number still had mobility problems.

\section{Results}

The results of the study represent the experiences of stroke patients and their spouses in Blantyre, Malawi. All participants were married and living together as husband and wife before the stroke and during the study. Four stroke patients were employed before the stroke but had not yet returned to work. Eight participants were retired officers, businessmen and farmers. At the time of the study none of the participants had returned to their previous occupations. The results are presented based on themes that emerged out of the analysis of participants' feelings and experiences.

\section{Stroke patients' experience of disability}

Under this theme two sub-themes emerged, namely, (i) impairment of basic functions and self-care, and (ii) inability to return to work and scarcity of medication.

\section{Impairment of basic functions and self-care}

When participants were asked to describe their life experiences with the illness they spontaneously mentioned impairments such as loss of mobility, generalised weakness of the body, urine incontinence, bowel dysfunction and memory loss that resulted in a state of helplessness. For example, one of the participants at his home in an urban setting with good social support from his children said:

"You find that you bave urinated on yourself without control so I preferred if possible that the patients should be given those pants (diapers) ... I am still using those pants." (MP.01)

Some of the stroke patients reported failing to perform basic activities of daily living such as eating. They also complained of a loss of mobility which meant their activities were limited, as illustrated in the following excerpts:

"Even eating is hard... they have to cut for me the food. To eat by myself I can't." (FP.01).

This participant was interviewed at her home in Mwanza rural setting. She had been abandoned by her daughters and family except her husband

"I was in a wheelchair. It means I was stuck ... so it's not easy. I could not go out." (MP.02) This participant was interviewed at the centre, he was able to drive at that time, and he lived in Blantyre urban. He lacked social support from friends.

\section{Inability to return to work and scarcity of medication}

The majority of participants indicated that stroke had serious consequences on their economic activities and income with the worst conditions experienced when a breadwinner was not able to return to work. Other challenges mentioned included scarcity of drugs in public hospitals, settling of medical and rehabilitation bills, and managing transport costs, as indicated below:

"My problem is money, I was making money on daily basis but now I can't. This has a bad effect on my life ... I was getting a lot of money like K50 000.00 but these days I can't." (MP.03).

This participant was interviewed at the centre, had good support from brothers, wife and children, and lived in Blantyre rural.

"Drugs are not available when I go to Thyolo District Hospital. Likewise when I go to Bvumbwe Health Centre they are still missing." (MP.04).

This participant was interviewed at his house in Thyolo and lacked social support from friends and relatives

\section{Spouses' experiences of caring for a disability due to stroke}

The sub-themes related to the above theme as described by spouses were challenges of care-giving and dealing with cognitive problems and anger.

\section{Challenges of care-giving}

The majority of spouses indicated that they were devastated by the demands of care-giving especially when patients were dependent in self-care, had speech problems and faecal and urine incontinence. The results indicate that female spouses were more burdened by the care-giving task than male spouses. However, both male and female spouses indicated that caring for their partner negatively affected their daily routines, including participation in religious activities as illustrated by the following quotation:

"Like at the beginning it meant that everything had to be done for bim. Like feeding him, whether he wants to go to the toilet, everything. Escorting him to the hospital, dressing him, everything and you realise you need a number of people to be helping you if there is a chance."

(FP.02) Participant (spouse) was interviewed at her home in Chiradzulu and had good support from her children including a man hired to help with transfers while at the centre.

"But to find a chance to leave the patient and go somewhere is not possible. Now I have stayed a number of weeks without going to church." (MP.05)

Participant (spouse) was interviewed at her home in Thyolo (Bumbwe), she had no social support from family and 
relatives.

\section{Dealing with cognitive problems and anger}

The results demonstrate that spouses experienced challenges in caring for patients with cognitive disorders such as confusion, emotional liability and anger. The majority of spouses described the patients' anger as excessive and far beyond control. However, the general consensus was that caring for stroke patients requires perseverance, as indicated below:

"The care of a person who has suffered a stroke is a little difficult. What seems difficult is that sometimes the brain does not work properly so it requires the guardian to be persevering in a lot of things. "(FP.03)

Participant interviewed at the centre, she had good support from family and relatives lived in Blantyre rural.

"For me, the anger was there previously of course, he was angry a lot but now the anger is increased beyond control. Some of the maids who used to work for us have resigned and left us because of the same anger." (FGD 2)

\section{Experience of participants with rehabilitation}

When patients and spouses were requested to give their opinion of the rehabilitation centre, different views came up. They mentioned inadequate space resulting in delayed admission, poor condition of the wards and treatment rooms, inadequate toilets and bathrooms as problem areas:

"My daughter took us to the centre. After they examined bim we were told there was no space so they could not hospitalise him but we had to come another day." (FP.04)

Participant interviewed at the rehabilitation centre, had good support from family and children

"But on top of that the rooms, the treatment rooms ... I think the rooms need to be improved because I think now as it is they just separated by putting wooden boards... Even the beds if there could be beds like the ones in OPD1 it's nice." (FGD 1)

"My stay at the rehabilitation centre was good but the only problem was bathing; bathrooms are not enough. There was one bathroom for patients and one for the guardians so we were waiting on a queue to get into the shower." (FP.06)

Participant interviewed at her home in Mulanje, had support from relatives and neighbourhood at first but later it deteriorated.

\section{Discussion}

The aim of the study was to explore the challenges and experiences of stroke patients and their spouses in Blantyre, Malawi. The identified challenges include stroke patients' experiences of disability, spouses' experiences of caring for disability due to stroke and participants' experiences with rehabilitation.

\section{Stroke patients' experience of disability}

The findings indicate that the stroke patients struggled to perform physical activities which consequently caused limitations in performing basic activities of daily living (ADLs) and self-care. In addition, activity limitations interfered with their social interaction. These findings are similar to the findings of a study conducted by Carod-Artal et al which highlighted that post-stroke disability reduces satisfaction with life and causes isolation and diminished social participation as a result of physical disability ${ }^{28}$. Several studies have also indicated that stroke patients experience a number of physical challenges such as loss of mobility, including walking and hand function which are major determinants of quality of life after stroke $e^{3,4,29,30}$. This experience of disability was mentioned particularly by three participants (MP, 01, FP 01 and MP 02) during in-depth interviews and was repeated during focus group discussions.

Some participants (MP 06, MP 04 and FP 02) reported that they were struggling to obtain basic necessities such as food and medication due to lack of money as they had been unable to return to work after the stroke. It was also a challenge to get blood pressure medication due to the scarcity of medication in public hospitals and the high cost of medication in private hospitals and pharmacies. Consequently, patients were buying medication from uncertified places and people such as vendors. Some participants reported selling their food to buy medicine. Furthermore, high transport costs made it difficult for them to visit their relatives at the centre. The relevant literature indicates that working adults' inability to return to work results in increased unmet financial needs and has a detrimental effect on family life ${ }^{31}$. In addition, Urimubenshi et $\mathrm{a}^{11}$ found that in Rwanda stroke survivors and spouses who were unemployed and were not involved in incomegenerating activities had difficulty in affording transportation to hospital and in paying their hospital bills ${ }^{11}$. This state of affairs interfered with their rehabilitation outcomes. From the findings of this study, it can be inferred that scarcity of medication predisposed the patients to recurrent stroke. In the same way, it can be argued that a lack of rehabilitation facilities and of professionals in the community negatively affected the patients' outcome. However, a lack of finances could be a barrier to accessing these rare services even if they were present in the community. There is a need, therefore, for a multi-disciplinary team to ensure that medication and rehabilitation services are made available to the people within the community through the provision of public health facilities at affordable rates.

\section{Spouses' experience of caring for a patient with a disability due to stroke}

The findings related to caring for a patient with a disability due to stroke were consistent with the findings of Wu et al and $\mathrm{CaO}$ et $\mathrm{al}^{9,32}$ who found that spouses of stroke patients were required to perform nearly all basic ADLs for the patients, such as transporting the patients, helping with toiletries, dressing and grooming, pressure sore prevention, issuing of medication at scheduled times, proper positioning of patients and modification of the home environment. Furthermore, Thompson and Walker ${ }^{12}$ found that spouses change their initial role from spouse to caregiver due to additional responsibilities and duties previously carried out by the spouse. Similarly, Cao et $\mathrm{al}^{32}$ describe this change of role as a shift from a wife to a mother. Moreover, caregiving was found to be more challenging when patient had cognitive and anger problems. Thus social support from family and friends is considered valuable at this stage as it reduces physical and psychological strain ${ }^{33,34}$.

Some participants (FP 02, FP 05) reported that the carehttps://dx.doi.org/10.4314/mmj.v31i2.2 
giving responsibility was interfering with their current jobs. In the case of participant (FP 02), she received a warning from her employers as she was often required to escort her spouse to the hospital. Similarly, Forsberg-Warleby et $\mathrm{a}^{35}$ found that there was a decline in occupation and leisure activities among spouses of patients with self-care needs. Both Cameron and Rudman ${ }^{36,37}$ found that both stroke survivors and their carers were deeply enmeshed by the illness and that spouses experienced emotional distress due to lack of participation in valued leisure activities. Based on the literature and the findings above, it is apparent that spouses agonise about care-giving responsibilities that hinder them from engaging in work and leisure activities among other things. Lack of leisure activities such as physical exercise may predispose the spouses to life-style diseases such as diabetes, heart diseases or stroke, which may negatively affect the care-giving process. The study reported in this article emphasizes the need for social support from family and friends.

\section{Participants' experience of rehabilitation}

In the present study participants (MP 02, FP O2, FP 06, MP 06 \& FP 05) indicated that when they came for admission there was a lack of space at the centre and they had no choice but to return home and wait until they could be admitted. This situation caused a delay in the required intervention. In addition, one participant (MP 02) reported that therapy rooms and beds - especially in the outpatients' section were in very poor condition and needed to be replaced. Some participants (MP 02, MP 06, MP 07 \& FP 06) reported that the centre was overcrowded and that the toilets and bathrooms were so inadequate that patients were queuing to get into the shower. As a result, they had to start showering around $02: 30 \mathrm{hrs}$ in order to finish before therapy time and this was extremely challenging in winter. Evidence from the literature has shown that rehabilitation improves physical function in stroke patients ${ }^{38}$. However, Moser et al ${ }^{39}$ found that delayed intervention directly increased morbidity and mortality among stroke patients.

A decade ago Farin et $\mathrm{al}^{40}$ reported that the standard of rehabilitation services in Germany was high. In the Netherlands, 26 adult rehabilitation centres served a population of 16 million people and every university and general hospital offered outpatient rehabilitation services ${ }^{16}$. In contrast, Malawi has a population of over 15 million with only one adult rehabilitation centre ${ }^{7,41}$. The centre is challenged to meet the increased demand for rehabilitation services ${ }^{41}$. The findings of the current study indicate that stroke patients have difficulty in accessing rehabilitation services because of limited space at the centre. This results in delayed intervention, which worsens the disability. Therefore, it is suggested that measures be taken to provide more space for patients and improve the living conditions of patients at the centre. There is also an urgent need to increase the number of facilities nation-wide. The findings of this study are mostly known in other countries but are reasonably new in the Malawian context. However, particular to Malawi the patients pointed out that there was inadequate bed space, poor services with regards to toilets, bathrooms and treatment rooms at the rehabilitation centre. Furthermore, spouses reported that it was too difficult to care for a patient with faecal incontinence, speech impairment and anger management problems. These findings differ from those reported in other countries.

\section{Conclusion}

The findings of this study have highlighted that stroke patients feel helpless with mobility loss, urine and bladder incontinence and limited accessibility to rehabilitation services. Other challenges included financial challenges that came with inability to return to work, and scarcity of medication in district hospitals and health centres. The study further highlights inadequate space at the rehabilitation centre which delayed the onset of the rehabilitation process. In this connection, the study reveals that the centre has limited treatment rooms, toilets and showers available for patient use. Feedback from spouses of patients shows that care-giving was most difficult when the patients had faecal incontinence, speech impairment and problems with anger management.

\section{Limitations}

We acknowledge that the number of participants in the focus group discussion was less than the recommended 6 to 12 participants. Being a qualitative study with a small sample size, the findings may not be generalised. Since the analysis was manually done by the principle researcher, there was room for bias.

\section{Recommendations}

Since the findings highlight scarcity of medication in district hospitals and health centres we recommend improved accessibility of medication at all levels of health service delivery to reduce both prevalence and recurrence of stroke. We also recommend improved access to rehabilitation services for better outcome in stroke patients which consequently reduces the burden of care-giving. Furthermore, it is recommended that Kachere Rehabilitation Centre should improve service delivery with regard to toilets and showers and treatment rooms. Finally, we recommended that more research should be done in this area of knowledge especially in the Central and Northern regions of the country which were not included in the current study.

\section{Acknowledgements}

We are grateful to all the authorities who gave us permission to conduct the study and to SACORE for the sponsorship. We appreciate the contributions made by the participants in this study and by all those who assisted in one way or the other.

\section{References}

1. World Health Organisation. The WHO STEPwise approach to stroke surveillance. In: WHO STEPS Mannual. 2005. p. 1-22.

2. Johnston SC, Mendis S, Mathers CD. Global variation in stroke burden and mortality : estimates from monitoring, surveillance, and modelling. Lancet Neurol. 2009;8(4):345-54.

3. Ng AMC, French D, Mclean N. Coping with the Challenges of Long Term Perspectives of Stroke support Group Members. J Health Psychol. 2008;13(8):1136-46.

4. Teasell R, Nestor B, Heitzner J. Clinical Consequences of Stroke. Evid Based Rev Stroke Rehabil. 2008;(July):1-19.

5. Connor MD, Walker R, Modi G, Warlow CP. Burden of stroke in black populations in sub-Saharan Africa. Lancet Neurol. 2007;6:26978.

6. Walker RW, Mclarty DG, Masuki G, Kitange HM, Whiting D, 
Moshi AF, et al. Age specific prevalence of impairment and disability relating to hemiplegic stroke in the Hai District of northern Tanzania. J Neurosurg Psychiatry. 2000;68:744-9.

7. Peterson C, Hargis J, Nesbit C, Peterson C. Malawi's Physiotherapists: Implications for Clinical Faculty Development in Resource-Limited Regions of the World. J Phys Ther Educ. 2013;27(2).

8. Mackay J, Mensah GA. The atlas of heart disease and stroke. J Hum Hypertens. 2005;19(505):9240.

9. Wu C. Learning to be a family caregiver for severely debilitated stroke survivors during the first year in Taiwan. 2009.

10. Das S, Hazra A, Ray BK, Ghosal M, Banerjee TK, Roy T, et al. Burden Among Stroke Caregivers: Results of a Community-Based Study From Kolkata, India. J Am Heart Assoc. 2010;41:2965-8.

11. Urimubenshi G, Rhoda A. Environmental barriers experienced by stroke patients in Musanze district in Rwanda : a descriptive qualitative study. Afr Health Sci. 2011;11(3):398-406.

12. Thompson S, Walker L. Sexual Dysfunction after Stroke : Underestimating the Importance of Psychological and Physical Issues Sexual Dysfunction after Stroke: Underestimating the Importance of Psychological and Physical Issues. WebmedCentral Phys Med. 2011;2(12):1-12.

13. Mcpherson CJ, Wilson KG, Chyurlia L, Leclerc C. The caregiving relationship and quality of life among partners of stroke survivors : A cross- sectional study. Health Qual Life Outcomes. 2011;9(29):1-10.

14. Haley WE, Roth DL, Howard G, Safford MM. Caregiving Strain and Estimated Risk for Stroke and Coronary Heart Disease Among Spouse Caregivers Differential Effects by Race and Sex. Stroke. 2010;41:331-6.

15. Perkins M, Howard VJ, Wadley VG, Crowe M, Safford MM, Haley WE, et al. Caregiving Strain and All-Cause Mortality : Evidence From the REGARDS Study. J Gerontol Ser B Psychol Sci Soc Sci. 2012;68(4):504-12.

16. Beckerman $\mathrm{H}$, Roelofsen EE. The value of the Rehabilitation Activities Profile ( RAP ) as a quality sub-system in rehabilitation medicine. Disabil Rehabil. 2004;26(7):387-400.

17. Chimatiro G, Rhoda A. Environmental barriers to reintegration experienced by stroke clients post discharge from a rehabilitation centre in Malawi. SA J Physiother. 2013;70(1):20-5.

18. Morrow SL. Quality and Trustworthiness in Qualitative Research in Counseling Psychology. J Couns Psychol. 2005;52(2):250-60.

19. World Health Organisation. Country Cooperation Stratergy at a glance. 2017.

20. Babbie S. The practice of social research. 2007. 1-304 p.

21. Mack N, Woodsong C, Macqueen K, Guest G, Namey E. Qualitative Research Methods: A Data Collector's Field Guide. Fam Heal Int. :2849 .

22. Powell RA, Single M. Methodology Matters-V. Int J Qual Heal Care. 1996;8(5):499-504.

23. Burnard P, Gill P, Stewart K, Treasure E, Chadwick B. Analysing and presenting qualitative data. Br Dent J. 2008;204(8):429-32.

24. Hsieh H-F, Shannon SE. Three Approaches to Qualitative Content Analysis. Qual Heal TResearch. 2005;15(9):1277-88.

25. Krefting L. Rigor in Qualitative Research: The Assessment of Trustworthiness. Am J Occup Ther. 1991;45(3):214-22.
26. Lincoln YS, Guba EG. Criteria for assessing naturalistic inquiries as reports. 1988.

27. Lietz CA, Langer CL, Furman R, Lietz CA, Langer CL. Establishing Trustworthiness in Qualitative Research in Social Work. Qual Soc Work. 2006;5(4):441-58.

28. Carod-artal J, Egido A, Gonza L, Seijas EV De. Quality of Life Among Stroke Survivors Evaluated 1 Year After Stroke Experience of a Stroke Unit. Stroke. 2000;31:2995-3000.

29. Nichols-larsen DS, Clark PC, Zeringue A, Greenspan A, Blanton S. Factors Influencing Stroke Survivors ' Quality of Life During Subacute Recovery. Stroke. 2005;36:1480-5.

30. Thompson HS, Ryan A. The impact of stroke consequences on spousal relationships from the perspective of the person with stroke. J Clin Nurs. 2009;18:1803-11.

31. Daniel K, Wolfe CDA, Busch MA, Mckevitt C, Busch MA, Mckevitt C. What are the Social Consequences of Sroke for Working Aged Adults? : A systematic Review. J Am Heart Assoc. 2009;40:e43140 .

32. Cao V, Chung C, Ferreira A, Nelken J, Brooks D, Cott C. Changes in Activities of Wives Caring for Their Husbands Following Stroke. Physiother Canada. 62(1):35-43.

33. Bøen H, Dalgard OS, Bjertness E. The importance of social support in the associations between psychological distress and somatic health problems and socio-economic factors among older adults living at home : a cross sectional study. BMC Geriatr. 2012;12(1):1.

34. Visser-meily A, Post M, Port I Van De, Maas C, Forstberg-wärleby G, Visser-meily A, et al. Psychosocial Functioning of Spouses of Patients With Stroke From Initial Inpatient Rehabilitation to 3 Years Poststroke. J Am Heart Assoc. 2009;40:1399-404.

35. Forsberg-wa G, Mo A, Blomstrand C. Life satisfaction in spouses of patients with stroke during the first year after stroke. J Rehabil Med. 2004;36(1):4-11.

36. Cameron JI, Cheung AM, Streiner DL, Coyte PC, Stewart DE. Stroke Survivor Depressive Symptoms Are Associated With Family Caregiver Depression During the First 2 Years Poststroke. J Am Heart Assoc. 2011;42:302-6.

37. Rudman DL, Herbert D, Reid D. Living in a restricted occupational world: The occupational experiences of stroke survivors who are wheelchair users and their caregivers. Cannadian J Occup Ther. 2006;73(I):141-52.

38. Foley AA, Hillier SB, Barnard RA. Evaluation of a geriatric day rehabilitation centre : subjective and objective outcomes in communitydwelling older adults. Aust J Prim Health. 2009;1997(January):117-22.

39. Moser DK, Kimble LP, Alberts MJ, Alonzo A, Croft JB, Dracup $\mathrm{K}$, et al. Reducing Delay in Seeking Treatment by Patients With Acute Coronary Syndrome and Stroke A Scientific Statement From the American Heart Association Council on Cardiovascular Nursing and Stroke Council. Circulation. 2006;114:168-83.

40. Farin E, Follert P, Gerdes N, Jackel W, Thalau J. Quality assessment in rehabilitation centres : the indicator system "Quality Profile." Disabil Rehabil. 2004;26(18):1096-104.

41. Mulwafu W. Gap Analysis for the National Health Research Agenda of Malawi: Research Priorities for the Themes Trauma and Rehabilitation. 2010; 1-26. 